\title{
Principais fatores de risco associados ao desenvolvimento do câncer de colo do útero, com ênfase para o Papilomavírus humano (HPV): um estudo de revisão
}

Main risk factors associated with the development of cervical cancer, with an emphasis on human papillomavirus (HPV): a review study

Principales factores de riesgo asociados con el desarrollo de cáncer de cuello uterino, con énfasis en el papillomavirus humano (VPH): un estudio de revisión

Carmem Mariana Carneiro Almeida ORCID: https://orcid.org/0000-0002-7774-7634 Faculdade Nobre de Feira de Santana, Brasil

E-mail: karmem_mariana_13@hotmail.com

ORCID: https://orcid.org/0000-0003-1681-0174 Unidade de Ensino Superior de Feira de Santana, Brasil E-mail: alineneves013@gmail.com

Rebeca Silva Bezerra

ORCID: https://orcid.org/0000-0003-2864-7327 Unidade de Ensino Superior de Feira de Santana, Brasil E-mail: rebecabezerra23@gmail.com

Felicson Leonardo Oliveira Lima ORCID: https://orcid.org/0000-0001-5256-6768 Faculdade Nobre de Feira de Santana, Brasil E-mail: felicsonleonardo@hotmail.com

Tasciano dos Santos Santa Izabel ORCID: https://orcid.org/0000-0003-0631-5217 Unidade de Ensino Superior de Feira de Santana, Brasil Universidade Estadual de Feira de Santana, Brasil E-mail: tascianounef@gmail.com

\begin{abstract}
Resumo
Objetivo: Descrever os principais fatores de risco para o desenvolvimento de câncer do colo do útero, enfatizando a infecção pelo HPV e a relevância da imunização na prevenção de neoplasia no colo uterino, além de discorrer aspectos imunológicos e os principais métodos diagnósticos. Metodologia: Foi realizada uma revisão da literatura, do tipo descritiva, com caráter qualitativo, mediante materiais indexados nas plataformas PubMed, SciELO e no portal de periódicos CAPES, após busca e aplicação dos critérios de inclusão e exclusão, foram selecionados um total de 52 arquivos, publicados entre os anos de 2010 a 2020 e redigidos nos idiomas: português, inglês e espanhol. Resultados e Discussão: Os casos de câncer do colo do útero possuem como fator principal as infecções ocasionadas pelo HPV. Ainda assim, podem ser citados também: as infecções pelo vírus Herpes simples tipo II, o uso de corticoides, multiplicidade de parceiros, tabagismo, baixa ingestão de vitaminas, baixa condição socioeconômica, uso de anticoncepcionais, práticas homossexuais e bissexuais, início precoce da atividade sexual, imunossupressão, multiparidade e infecções pela Chlamydia trachomatis. Conclusão: Em suma, com base nos instrumentos científicos utilizados foram demonstrados os diversos fatores associados ao câncer do colo uterino. Em contrapartida, a prevenção de infecções pelo HPV, mediante vacinação é um importante instrumento para a redução das chances de complicações futuras.
\end{abstract}

Palavras-chave: Infecção por Papilomavírus Humano; Neoplasias do colo uterino; Papanicolau.

\begin{abstract}
Objective: To describe the main risk factors for the development of cervical cancer, emphasizing HPV infection and the relevance of immunization in the prevention of cervical cancer, in addition to discussing immunological aspects and the main diagnostic methods. Methodology: A descriptive literature review was carried out, with a qualitative character, using materials indexed on the PubMed, SciELO platforms and on the CAPES journals portal, after searching and applying the inclusion and exclusion criteria, a total of 52 files were selected, published between 2010 and 2020 and written in the languages: Portuguese, English and Spanish. Results and Discussion: The cases of cervical cancer have HPV infections as the main factor. Still, the following can also be mentioned: infections by the Herpes simplex virus type II, the use of corticosteroids, multiple partners, smoking, low vitamin intake, low socioeconomic status, use of contraceptives, homosexual and bisexual practices, early onset of activity sexual
\end{abstract}


intercourse, immunosuppression, multiparity and Chlamydia trachomatis infections. Conclusion: In summary, based on the scientific instruments used, the various factors associated with cervical cancer were demonstrated. In contrast, the prevention of HPV infections through vaccination is an important tool for reducing the chances of future complications.

Keywords: Papillomavirus Infections; Uterine cervical neoplasms; Papanicolau.

\section{Resumen}

Objetivo: Describir los principales factores de riesgo para el desarrollo de cáncer de cuello uterino, enfatizando la infección por VPH y la relevancia de la inmunización en la prevención del cáncer de cuello uterino, además de discutir los aspectos inmunológicos y los principales métodos de diagnóstico. Metodología: Se realizó una revisión descriptiva de la literatura, con carácter cualitativo, utilizando materiales indexados en las plataformas PubMed, SciELO y en el portal de revistas CAPES, luego de buscar y aplicar los criterios de inclusión y exclusión, se seleccionaron un total de 52 archivos, publicado entre 2010 y 2020 y escrito en los idiomas: portugués, inglés y español. Resultados y Discusión: Los casos de cáncer de cuello uterino tienen como principal factor a las infecciones por VPH. Aún así, también se pueden mencionar: infecciones por el virus del Herpes simple tipo II, uso de corticosteroides, múltiples parejas, tabaquismo, baja ingesta de vitaminas, bajo nivel socioeconómico, uso de anticonceptivos, prácticas homosexuales y bisexuales, inicio temprano de actividad relaciones sexuales, inmunosupresión, multiparidad e infecciones por Chlamydia trachomatis. Conclusión: En resumen, con base en los instrumentos científicos utilizados, se demostraron los diversos factores asociados al cáncer de cuello uterino. Por el contrario, la prevención de las infecciones por VPH mediante la vacunación es una herramienta importante para reducir las posibilidades de complicaciones futuras.

Palabras clave: Infecciones por Papillomavirus; Neoplasias del cuello uterino; Papanicolau.

\section{Introdução}

O câncer do colo do útero (CCU) é uma neoplasia caracterizada pela replicação desordenada de células anômalas, acometendo o epitélio de revestimento do colo uterino, tendo como principal região de agressão, a ectocérvice. O carcinoma epidermóide do epitélio escamoso representa cerca de $90 \%$ dos casos de CCU, outra importante neoplasia é o adenocarcinoma, este acomete a endocérvice nas células glandulares e representa aproximadamente 10\% dos casos (De Oliveira et al., 2019; Brasil, 2020).

No Brasil, o câncer de colo do útero é a terceira causa de morte por câncer em mulheres em todo o país. Entre a faixa etária mais predisponente ao desenvolvimento de CCU, estão as mulheres com idade entre 25 a 64 anos, com vida sexual ativa. Estima-se que no mundo, todos os anos são diagnosticados aproximadamente 570 mil novos casos de CCU, sendo esta a quarta maior causa de câncer em mulheres, responsável por 311 mil óbitos anuais (Duarte, 2019; Brasil, 2020; Tallon et al., 2020).

Os fatores que podem acarretar no desenvolvimento do CCU relacionam-se principalmente com a persistência da infecção pelo Papilomavírus humano (HPV), este por sua vez, abriga a capacidade em alterar as células da cérvice. O HPV possui 200 genótipos, sendo classificados de baixo grau os tipos não oncogênicos e de alto grau para os tipos oncogênicos. Estima-se que os tipos 16 e 18 provocam 70\% dos casos de câncer no colo do útero no mundo (Reis \& Piedade, 2019; Brasil, 2020; Da Silva et al., 2020).

O exame Papanicolau, também conhecido como esfregaço cervicovaginal é realizado para o rastreio de câncer no colo do útero, possibilitando a verificação de possíveis alterações citopatológicas através da coleta citológica da ectocérvice e endocervice. A nomenclatura para essas alterações segue o Sistema Bethesda de 2001 que foi implementado para laudos pela Sociedade Brasileira de Citopatologia (Silva et al., 2017; Dias et al., 2019).

De forma geral, as alterações do epitélio de revestimento são classificadas em lesão intraepitelial escamosa de baixo grau (LSIL); as alterações no epitélio pavimentoso são categorizadas em lesão intraepitelial escamosa de alto grau (HSIL) o que inclui o carcinoma in situ (acomete todo o revestimento do epitélio). Quando na endocérvice, os danos nas células glandulares podem ser rotulados em adenocarcinoma in situ. Por fim, quando não se consegue determinar o tipo de lesão em células escamosa segue as seguintes classificações: Células escamosas atípicas de significado indeterminado possivelmente não neoplásico (ASC-US); Células escamosas atípicas não sendo possível excluir lesão intraepitelial de alto grau (ASC-H) 
(Lodiet al.,2012; Dalla, 2016; Bao et al., 2020).

O presente estudo objetivou descrever os principais fatores de risco associados ao desenvolvimento de câncer do colo do útero, enfatizando a infecção pelo HPV e a relevância da imunização na prevenção de neoplasia no colo uterino, além de discorrer aspectos imunológicos e os principais métodos diagnósticos.

\section{Metodologia}

Para Pereira (2018), a definição de pesquisa bibliográfica é caracterizada como um estudo realizado a partir de fontes secundárias de informações, deste modo, há o embasamento e construção do estudo, mediante análise dos conteúdos encontrados, sobre a temática buscada, já relatadas e afirmadas por estudos e pesquisadores anteriores. As fontes utilizadas para este tipo de pesquisa envolvem artigos, livros, teses, dissertações e outros materiais de respaldo científico. O autor ainda afirma que a pesquisa descritiva busca explanar detalhes de uma realidade analisada, sendo útil na identificação de aspectos próprios de um determinado objeto de estudo, indo além de uma simples identificação da existência de relação entre variáveis.

Trata-se de uma revisão da literatura do tipo descritiva com abordagem qualitativa, a qual foi elaborada mediante analise de materiais indexados nas bases de dados PubMed, SciELO, e o portal de periódicos da CAPES, utilizando os termos: Infecção por Papilomavírus Humano; Neoplasias do Colo Uterino; Papanicolau, os quais resultaram na seleção de artigos, teses de mestrado, dissertações de doutorado e livros, transcritos nos idiomas: português, inglês e espanhol, publicados entre os anos de 2010 a 2020, cuja abordagem, relatavam os principais fatores para a causalidade do câncer do colo do uterino.

Para a realização desta pesquisa, alguns critérios de inclusão e exclusão foram aplicados. Os critérios de inclusão foram utilizados nos materiais que abordavam especificamente sobre o tema proposto, respeitando os objetivos do estudo e o recorte temporal. Os critérios de exclusão relacionaram-se aos conteúdos duplicados, publicados em fontes obscuras, com idiomas diferentes dos pré-estabelecidos e fora do recorte temporal.

A seleção foi esquematizada na seguinte ordem: (I) leitura exploratória; (II) leitura seletiva; (III) seleção do material em adequação aos objetivos da pesquisa. Ao final de todas as etapas, resultou-se no total de 539 arquivos, destes, 52 foram selecionados para a constituição do presente estudo.

\section{Resultados e Discussão}

De acordo com Simoes \& Junior (2019), o câncer de colo do útero, geralmente, cursa de forma assintomática, porém quando sintomas são manifestados, pode ocorrer sangramento anormal na vagina (após o sexo ou período de menopausa), apresentação de manchas de sangue entre os períodos menstruais ou prolongamento da menstruação ou intensidade de sangramento, dor na relação sexual e dor na região pélvica. Em estágios mais avançados de CCU é possível ocorrer inchaço das pernas, problemas na micção ou na evacuação, hematúria.

\subsection{Principais fatores de risco para o desenvolvimento do CCU}

De Almeida \& De Oliveira (2014) em consonância com Brasil (2020), apontam que a maior parte dos casos associado ao desenvolvimento do câncer de colo de útero estão ligados ao HPV (subtipo oncogênico com altas cargas virais), os autores ressaltam que o vírus em si não provoca o câncer, mas é um fator necessário para seu desenvolvimento devido a sua capacidade em provocar alterações celulares na região da cérvice que podem evoluir para lesões mais graves resultando então no desenvolvimento de células oncogênicas. Na Tabela 1 são discutidos os principais fatores para o desenvolvimento de CCU. 
Tabela 1. Fatores de risco para o desenvolvimento do CCU.

\begin{tabular}{|c|c|c|c|}
\hline AUTOR & TÍTULO & FATOR & DESCRIÇÃO \\
\hline $\begin{array}{l}\text { Santos et al., } \\
\quad(2010)\end{array}$ & $\begin{array}{l}\text { Percepção de usuárias } \\
\text { de uma unidade de } \\
\text { saúde da família acerca } \\
\text { da prevenção do câncer } \\
\text { do colo do útero. }\end{array}$ & $\begin{array}{l}\text { Infecções pelo vírus } \\
\text { Herpes simples tipo } \\
\text { II }\end{array}$ & $\begin{array}{c}\text { Este vírus esteve por cerca } \\
\text { de vinte anos em evidência, } \\
\text { caracterizado como o } \\
\text { principal fator de } \\
\text { desenvolvimento de CCU, } \\
\text { atualmente, o título foi } \\
\text { transpassado para o HPV, } \\
\text { no entanto, o herpes vírus } \\
\text { ainda abriga essa } \\
\text { capacidade. }\end{array}$ \\
\hline $\begin{array}{c}\text { Casarin \& Piccoli } \\
\text { (2011) }\end{array}$ & $\begin{array}{c}\text { Educação em saúde } \\
\text { para prevenção do } \\
\text { câncer de colo do útero } \\
\text { em mulheres do } \\
\text { município de Santo } \\
\text { Ângelo/RS }\end{array}$ & Uso de corticóides & $\begin{array}{l}\text { As pacientes em uso } \\
\text { crônico de corticóides } \\
\text { apresentam a possibilidade } \\
\text { de desenvolver CCU. }\end{array}$ \\
\hline $\begin{array}{l}\text { Costa et al., } \\
\quad(2011)\end{array}$ & $\begin{array}{l}\text { Prevenção do câncer de } \\
\text { colo do útero em } \\
\text { comunidades } \\
\text { ribeirinhas atendidas } \\
\text { pelo Programa Luz na } \\
\text { Amazônia, Estado do } \\
\text { Pará, Brasil }\end{array}$ & Múltiplos parceiros & $\begin{array}{l}\text { Os autores do presente } \\
\text { estudo apontam a } \\
\text { multiplicidade de parceiros } \\
\text { como fator de risco para } \\
\text { CCU. }\end{array}$ \\
\hline $\begin{array}{c}\text { Dos Anjos et al., } \\
\text { (2013) }\end{array}$ & $\begin{array}{l}\text { Fatores de risco para o } \\
\text { câncer de colo do útero } \\
\text { em mulheres reclusas }\end{array}$ & Tabagismo & $\begin{array}{l}\text { Neste estudo, foi observado } \\
\text { que } 44,5 \% \text { das pacientes } \\
\text { entrevistadas declararam ter } \\
\text { hábitos tabagistas o que } \\
\text { resulta em uma maior } \\
\text { suscetibilidade para o } \\
\text { desenvolvimento de lesões } \\
\text { cancerígenas. }\end{array}$ \\
\hline $\begin{array}{l}\text { Leite et al., } \\
\quad(2014)\end{array}$ & $\begin{array}{l}\text { Conhecimentos e } \\
\text { prática das mulheres } \\
\text { sobre câncer de colo do } \\
\text { útero de uma unidade } \\
\text { básica de saúde }\end{array}$ & $\begin{array}{l}\text { Baixa ingestão de } \\
\text { vitaminas }\end{array}$ & $\begin{array}{c}\text { A carência nutricional, bem } \\
\text { como a deficiências de } \\
\text { determinados compostos } \\
\text { mostram-se como } \\
\text { importantes causas de } \\
\text { desenvolvimento de CCU. }\end{array}$ \\
\hline $\begin{array}{l}\text { De Souza \& Costa } \\
\quad(2015)\end{array}$ & $\begin{array}{c}\text { Conhecimento de } \\
\text { Mulheres sobre HPV e } \\
\text { Câncer do Colo do } \\
\text { Útero após Consulta de } \\
\text { Enfermagem }\end{array}$ & $\begin{array}{l}\text { Baixa condição } \\
\text { socioeconômica }\end{array}$ & $\begin{array}{l}\text { Há evidencias cientificas } \\
\text { que apontam o } \\
\text { acometimento do CCU em } \\
\text { mulheres com nível } \\
\text { socioeconômico } \\
\text { desfavorável e/ou com } \\
\text { dificuldades no acesso aos } \\
\text { serviços de saúde. }\end{array}$ \\
\hline $\begin{array}{l}\text { Almeida \& Assis } \\
\text { (2017) }\end{array}$ & $\begin{array}{l}\text { Efeitos colaterais e } \\
\text { alterações fisiológicas } \\
\text { relacionadas ao uso } \\
\text { contínuo de } \\
\text { anticoncepcionais } \\
\text { hormonais orais }\end{array}$ & $\begin{array}{c}\text { Uso de } \\
\text { anticoncepcionais }\end{array}$ & $\begin{array}{l}\text { Utilizar anticoncepcionais } \\
\text { antes do desenvolvimento } \\
\text { completo do sistema } \\
\text { reprodutor pode ser um } \\
\text { fator importante para o } \\
\text { acometimento de CCU. } \\
\text { Ainda assim, o uso de } \\
\text { métodos contraceptivos } \\
\text { hormonais por tempo } \\
\text { superior a } 12 \text { anos, aumenta } \\
\text { os riscos para desenvolver } \\
\text { adenocarcinoma in situ do }\end{array}$ \\
\hline
\end{tabular}




\begin{tabular}{|c|c|c|c|}
\hline & & & colo uterino. \\
\hline $\begin{array}{l}\text { Yin F et al., } \\
\text { (2017) }\end{array}$ & $\begin{array}{l}\text { A novel trivalent HPV } \\
\text { 16/18/58 vaccine with } \\
\text { anti-HPV } 16 \text { and } 18 \\
\text { neutralizing antibody } \\
\text { responses comparable } \\
\text { to those induced by the } \\
\text { Gardasil quadrivalent } \\
\text { vaccine in rhesus } \\
\text { macaque model }\end{array}$ & Infecção pelo HPV & $\begin{array}{l}\text { O Papilomavírus Humano é } \\
\text { descrito como o principal } \\
\text { fator para a etiologia do } \\
\text { CCU, além disso, este é o } \\
\text { patógeno viral sexual mais } \\
\text { comum. }\end{array}$ \\
\hline $\begin{array}{l}\text { Crispim et al., } \\
\text { (2018) }\end{array}$ & $\begin{array}{l}\text { Assistência de } \\
\text { enfermagem à mulher } \\
\text { lésbica e bissexual na } \\
\text { atenção básica: } \\
\text { protocolo de } \\
\text { atendimento }\end{array}$ & $\begin{array}{c}\text { Práticas } \\
\text { homossexuais e } \\
\text { bissexuais }\end{array}$ & $\begin{array}{l}\text { As práticas sexuais do tipo } \\
\text { homossexuais e bissexuais } \\
\text { são descritas como fator de } \\
\text { risco para o CCU, o que } \\
\text { levanta a necessidade de } \\
\text { maiores cuidados, visto que } \\
\text { algumas mulheres e } \\
\text { profissionais da saúde } \\
\text { consideram de uma forma } \\
\text { equivocada a } \\
\text { invulnerabilidade destas, } \\
\text { para a aquisição de } \\
\text { infecções pelo HPV, } \\
\text { fazendo do rastreio do CCU } \\
\text { essencial para todas as } \\
\text { mulheres, independente da } \\
\text { orientação sexual. }\end{array}$ \\
\hline $\begin{array}{l}\text { Zandonade et al., } \\
\text { (2018) }\end{array}$ & $\begin{array}{l}\text { Mortalidade por câncer } \\
\text { de colo do útero no } \\
\text { espírito santo: } \\
\text { tendências temporais e } \\
\text { papel da enfermagem }\end{array}$ & $\begin{array}{l}\text { Início precoce da } \\
\text { atividade sexual }\end{array}$ & $\begin{array}{l}\text { Ao iniciar a vida sexual } \\
\text { muito jovem, as mulheres } \\
\text { terão um maior risco de } \\
\text { exposição ao HPV, além de } \\
\text { repetições desses quadros } \\
\text { infecciosos. O colo do útero } \\
\text { juvenil favorece a } \\
\text { penetração viral. }\end{array}$ \\
\hline $\begin{array}{l}\text { De Freitas et al., } \\
\qquad(2019)\end{array}$ & $\begin{array}{l}\text { Fatores de risco para o } \\
\text { câncer do colo uterino }\end{array}$ & Imunossupressão & $\begin{array}{l}\text { O comprometimento do } \\
\text { sistema imune na infecção } \\
\text { pelo HIV ou nos casos de } \\
\text { doenças autoimunes, } \\
\text { aumentam a probabilidade } \\
\text { de desenvolvimento do } \\
\text { CCU. }\end{array}$ \\
\hline $\begin{array}{l}\text { De Oliveira et al., } \\
(2020)\end{array}$ & $\begin{array}{l}\text { A não realização do } \\
\text { exame papanicolau e } \\
\text { comportamentos de } \\
\text { risco em mulheres com } \\
\text { vida sexual ativa }\end{array}$ & Multiparidade & $\begin{array}{l}\text { Mulheres com histórico de } \\
\text { três ou mais partos, } \\
\text { correlacionam-se com } \\
\text { maiores chances para o } \\
\text { desdobramento do CCU. }\end{array}$ \\
\hline $\begin{array}{l}\text { Reis-Góes et al., } \\
\text { (2020) }\end{array}$ & $\begin{array}{c}\text { Prevalence of } \\
\text { Chlamydia trachomatis } \\
\text { infection in the } \\
\text { brazilian female } \\
\text { population: a review } \\
\text { article }\end{array}$ & $\begin{array}{c}\text { Infecções pela } \\
\text { Chlamydia } \\
\text { trachomatis }\end{array}$ & $\begin{array}{c}\text { Pacientes infectados pela } C . \\
\text { trachomatis apresentam } \\
\text { uma maior susceptibilidade } \\
\text { a infecções pelo HPV e } \\
\text { outros microrganismos, } \\
\text { visto que o mesmo acarreta } \\
\text { em debilidades no sistema } \\
\text { imunológico. }\end{array}$ \\
\hline
\end{tabular}

Fonte: Autores (2021).

Diante do exposto, pode-se observar uma grande variabilidade de fatores interligados a etiologia do CCU, podendo 
ser citados: As infecções pelo vírus Herpes simples tipo II, (Santos et al., 2010), o uso de corticoides (Casarin \& Piccoli, 2011), multiplicidade em parceiros (Costa et al., 2011), tabagismo (Dos Anjos et al., 2013), a baixa ingestão de vitaminas (Leite et al., 2014), baixa condição socioeconômica (De Souza \& Costa, 2015), Uso de anticoncepcionais (Almeida \& Assis, 2017), infecção pelo HPV (Yin F et al., 2017), práticas homossexuais e bissexuais (Crispim et al., 2018), início precoce da atividade sexual (Zandonade et al., 2018), imunossupressão (De Freitas et al., 2019), multiparidade (De Oliveira et al., 2020) e infecções pela Chlamydia trachomatis (Reis-Góes et al., 2020).

Marcelino et al., (2020) apontam em seu estudo os riscos associados ao trabalho como importantes fatores para o acometimento do câncer de colo uterino, citando a exposição de trabalhadores que manuseiam fluidos de motores, tabaco (fábricas de cigarro), e ao tetracloroetileno (produtos de limpeza) nas lavanderias, além da exposição ocupacional a fungos e bactérias como susceptibilidades para o desenvolvimento de câncer de colo uterino.

No que se refere às deficiências nutricionais para o acometimento do CCU, Tassarin (2017) descreve que alguns nutrientes e compostos bioativos podem influenciar na expressão gênica, seja de forma direta ou indireta, mostrando assim, a importância da alimentação saudável e equilibrada.

Para Gavidia (2020), o déficit na ingestão de vitaminas do tipo A, C, E, betacaroteno e ácido fólico podem reduzir a capacidade das células sob a defesa de agressões virais, resultando na persistência do processo infeccioso, o que culmina no câncer cervical. Essa carência se remete também as baixas condições socioeconômicas.

\subsection{Características e Etiopatogenia do Papilomavírus humano}

Leto et al., (2011) definem o HPV como uma IST causada por um vírus não envelopado de tamanho variável, entre 50 a $55 \mathrm{~nm}$, pertencente à família do Papoviridae onde apresenta o DNA como material genético contendo 8.000 pares de base.

Amorim (2015) e Serravalle et al., (2015) sugerem que assim como os demais vírus, o HPV é um microrganismo intracelular obrigatório que possui tropismo por células epiteliais escamosas (pele e mucosa). O Papilomavírus Humano possui 200 genótipos e é classificado de acordo com seu potencial oncogênico (baixo a alto grau). Os tipos 6, 11, 40, 42, 54, 61, 70, 72, 81 são considerados de baixo grau e os tipos 16, 18, 31, 33, 35, 39, 45, 51, 52, 56, 58, 59, 68, 73 e 82 são de al to grau.

Para Wohlmeister (2015) e Santos (2018), o genoma do HPV é constituído por oito regiões abertas para leitura (Open Reading Frame - ORFs) e apenas uma região fechada (Long Control Region - LCR). O ORFs apresenta a região precoce codificando as proteínas não estruturais E1, E2, E4, E5, E6, E7, a região tardia que codifica as proteínas do capsídeo L1 e L2 e por fim, a região controladora (URR). As proteínas E6 e E7 são considerados como oncoprotéinas, sendo a E6 associada à supressão e consequentemente a proliferação tumoral (p53) e a proteína E7 com a destruição da proteína do retinoblastoma (pRB), correlacionando então com a capacidade o seu potencial carcinogênico.

Caixeta et al., (2014) afirmam que o papilomavírus humano possui epitéliotropismo cuja infecção ocorre na junção escamo-colunar (JEC), através de microtraumas na mucosa, acometendo a camada basal, região mais profunda, onde as células estão em constante diferenciação com alta taxa mitótica, o que é ideal para o ciclo intracelular do HPV. O vírus se liga as proteínas de superfície da célula onde o capsídeo sofre modificação pela ação da furina, clivando a proteína L2 possibilitando assim, o transporte do DNA viral para o núcleo da célula infectada.

O ciclo do HPV, descrito por Peixoto (2016) e Dos Santos (2019), consiste em cinco fases: infecção, manutenção do genoma, fase proliferativa, amplificação genômica e a liberação de partículas virais. A medida que as células basais vão sofrendo diferenciação o genoma viral é perpetuado no material genético das células cuja fonte permanece nas células basais mantendo este ciclo. As proteínas E1, E2, E4 e E5 participam da amplificação genômica. A liberação das partículas virais ocorre na camada superficial, onde as proteínas L1 e L2 formam o capsídeo para o empacotamento do DNA do HPV em forma de vírions sem que haja a ruptura das células hospedeiras. 
Em conjunto, Amorim (2015) e Peixoto (2016) retratam sobre a ação do sistema imunológico frente a infecção pelo HPV, o que controla a progressão das infecções promovidas por esse vírus em um período de um a dois anos, entretanto, ainda não se sabe ao certo os mecanismos que levam a persistência da infecção por HPV, acreditando-se que a proteína E5 esteja relacionado a este fator principalmente para os subtipos oncogênicos 16 e 18.

\subsection{Resposta Imune frente a infecção pelo HPV}

Segundo Feller et al., (2010), os mecanismos imunológicos contra a infecção do HPV ainda não são elucidados, o que faz com que surjam questionamentos frente ao porquê de alguns casos serem suprimidos pelo sistema imunológico e outros evoluírem. Em consonância, Fernandes et al. (2012) reiteram sobre a infecção viral às células da camada basal, afirmando que esse processo, por não causar lise celular com liberação dos vírions, tende a promover uma resposta imunológica tardia. Ainda assim, o que se entende é que as imunidades celulares e humorais atuam na defesa contra esse microrganismo invasor.

Nos estudos realizados por Lima (2011) e Neiva (2013) foram demonstrados que a resposta celular é mais eficiente quando comparada a reposta do tipo humoral, cuja presença de anticorpos contra o HPV só aparecem em 30\% a 50\% dos infectados. Logo, os linfócitos T CD4+ e T CD8+ estão relacionados com a regressão da HPV, todavia a proteína E5 vem sendo associada à inibição do Complexo Maior de Histocompatibilidade (MHC) da classe I de células de Langerhans que são células apresentadoras de antígeno, alterando a expressão do receptor TLR9, impossibilitando a ativação do linfócito T que consequentemente resulta na persistência deste vírus na mucosa da cérvice, geralmente pelos tipos oncóticos.

\subsection{Exames para o rastreamento do câncer do colo do útero}

Oliveira (2016) aponta o HPV como um fator considerável para o surgimento de CCU, diante disso o mesmo indica a realização da pesquisa para detecção de alterações promovidas por esse vírus por meio do exame Papanicolau, objetivando a verificação de possíveis alterações citopatológicas.

Para De Sá e Silva (2019), o Papanicolau, também conhecido como: citologia oncótica, exame preventivo do colo do útero ou Pap Test, é o exame realizado através da coleta do material da JEC, a partir daí, faz-se a busca microscópica para presença de células coílocitos, sendo esta uma alteração característica do HPV que pode acometer células intermediarias e superficiais onde ocorre o aumento nuclear e hipercromasia, avaliando a possível presença de lesões na cérvice, principalmente na região da ectocérvice.

Batero-Rosas (2017) e colaboradores citam a colonoscopia, um exame direto, que permite a visualização de lesões no colo uterino através da aplicação do ácido acético $4 \%$ que em contato com a mucosa desidrata as células e coagula as proteínas onde a evidencia de lesões será indicado pela acetobranqueamento, demonstrando a intensidade da lesão. Embora esta técnica permita uma leitura mais rápida, limita a deteç̧ão de casos que ainda não evoluíram para lesões provocadas pelo HPV, o que pode gerar um resultado falso negativo.

Silva et al., (2015) em seu estudo expõem os métodos mais utilizados para o diagnóstico diferencial do CCU pela detecção direta do HPV, sendo este a PCR (reação em cadeia da polimerase) e a captura hibrida $(\mathrm{CH})$. O PCR é método de diagnóstico, através de técnicas de biologia molecular, que utiliza o DNA viral para o sequenciamento genômico, podendo utilizar primers para determinar o tipo especifico do genótipo do HPV ou primers para determinar apenas a presença de HPV sem identificação do genótipo. A $\mathrm{CH}$, por sua vez, é um exame quanti-qualitativo que também utiliza a técnica de biologia molecular sob hibridação do material genético do HPV, onde a reação enzima-substrato que permite a visualização dos híbridos pela quimiluminescência. A CH não consegue determinar o genótipo do Papilomavírus Humano, determinando apenas os grupos de baixo a alto grau pela quantificação da carga viral da amostra.

Para Ybaseta-Medina et al., (2014), a biopsia é o exame mais invasivo que confirmação do CCU ou a existência de 
pré-câncer, mediante a verificação no exame citológico com alterações sugestivas para câncer.

Martínez et al., (2015) descrevem três tipos de biopsia: biópsia colposcópica, curetagem endocervical e biópsia de cone (procedimento eletro cirúrgico de alça e biópsia de cone de faca fria). A biópsia colposcópica realiza uma seção na superfície da região anômala para verificar a histologia do tecido. A curetagem endocervical é feita caso não seja possível visualizar na colposcopia a região anormal, realizando então uma raspagem da endocérvice com uma cureta ou uma escova. A biópsia de cone, por sua vez, realiza um corte tecidual em formato de cone onde a base se refere a ectocérvice e ápice do cone é referente a endocérvice, apresentando também a região da JEC. Para esse tipo de corte pode ser feito pelo procedimento de excisão eletrocirúgica de alça ou por biópsia de cone de faca fria.

\subsection{Vacinação}

Rodrigues et al., (2019) definem a existência de dois tipos de vacinas contra o Papilomavírus humano: a vacina profilática e a terapêutica. A vacina profilática atua no estímulo do desenvolvimento de uma resposta humoral que será elucidada a partir do contato com as "partículas similares ao vírus" ou vírus-like particles (VLP), estruturas ausentes de DNA viral, que por sua vez, mostram-se muito eficazes em pacientes que nunca tiveram contato com o Papilomavírus anteriormente. O VLP gera no corpo humano a produção de anticorpos, estes, distribuem-se na mucosa genital, combatendo de modo prévio o HPV e consequentemente, a instalação da infecção. As vacinas terapêuticas, por sua vez, são sintetizadas a partir de peptídeos, DNA de plasmídeos, células dendríticas ou proteínas recombinantes, atuando na modulação da progressão da resposta imune celular, ao sensibilizar células imunocompetentes para o combate à infecção, cabendo ressaltar que seu emprego na terapêutica primária não demonstra grande eficácia.

Segundo Brasil (2017), o sistema único de saúde brasileiro oferece dois tipos de vacinas para HPV como medida profilática primária para o câncer do colo uterino, sendo a quadrivalente para os tipos de HPV de baixo grau 6 e 11 e de alto grau 16 e 18 e a bivalente apenas para os tipos 16 e 18. A metodologia de imunização para ambas as vacinas são duas doses com intervalo 6 meses administrada por via intramuscular. De forma geral, a indicação da ANVISA para aplicação da vacina quadrivalente permeia pela faixa etária entre 9 a 45 anos de idade e a bivalente a partir de 9 anos e sem restrições para demais idades. Assim como as demais vacinas, ocorre a estimulação da produção de anticorpos para os tipos de HPV presentes na constituição vacinal.

Para Da Silva et al., (2020) e Eufrasio et al., (2020), o emprego dos imunobiológicos (vacinas) diferem-se dependendo do gênero a ser aplicado. Para a população masculina, é indicado o imunobiológico Gardasil tetravalente (4vHPV), cuja composição demonstra potencial para atuar nos vírus do tipo HPV- 6, 11, 16 e 18, e a nonavalente (9vHPV), sob os tipos 6, 11, $16,18,31,33,45,52$ e 58 . No que se destina a população feminina, indica-se a vacina bivalente para atuação no combate dos vírus 16 e 18 Cervarix, bem como a vacina tetravalente.

Casarin e Piccoli (2011) e Eufrasio et al., (2020) descrevem que devido as altas taxas de incidência, a prevenção das infecções pelo HPV faz-se a melhor alternativa, visto que existe um grande número de lesões e doenças associadas a este vírus. A prevenção primária apresenta uma maior relevância para o sexo masculino, evitando a infecção inicial, sendo elementos deste tipo de prevenção: a circuncisão, o uso regular do preservativo e a vacinação. A prevenção mediada pela vacinação demonstra eficácia na regressão de lesões associadas ao HPV em mulheres com até 45 anos.

\section{Conclusão}

Mediante análise dos materiais que constituem o presente estudo foram demonstrados os diversos fatores associados ao acometimento do câncer do colo uterino, em especial, os quadros infecciosos promovidos pelo Papilomavírus humano. Ainda assim, cabe ressaltar os impactos a saúde vinculados a baixa condição socioeconômica de uma população, bem como as 
suas consequências, como a má alimentação e/ou carência nutricional, o que pode estar vinculado as altas taxas de mortalidade por CCU em mulheres no Brasil e nos países em desenvolvimento.

É importante destacar a relevância da vacinação, como forma de prevenção de infecções pelo HPV, reduzindo as chances de complicações futuras pela exposição a este vírus. O diagnóstico precoce influirá diretamente em melhores perspectivas de vida para a acometida, tendo o Papanicolau como um exame diagnóstico muito preciso para a elucidação inicial de alterações citopatológicas no colo uterino.

A carência de pesquisas para explicar os mecanismos imunológicos frente a infecção pelo HPV ainda é uma realidade, bem como maiores detalhes sobre o processo de infectividade e patogenicidade do mesmo, o que requer a execução de estudos futuros para elucidar estas pontuações.

\section{Referências}

Almeida, A. P. F. D., \& Assis, M. M. D. (2017). Efeitos colaterais e alterações fisiológicas relacionadas ao uso contínuo de anticoncepcionais hormonais orais. Rev Eletron Atualiza Saúde, 5(5), 85-93.

Amorim, A. T. (2015). Análise da coinfecção entre ureaplasmas e o vírus do Papiloma Humano (HPV) em amostras cervicais e em um modelo de estudo in vitro de queratinócitos primários humanos (PHK) (Doctoral dissertation, Universidade de São Paulo).

Bao, H., Sun, X., Zhang, Y., Pang, B., Li, H., Zhou, L., \& Wang, L. (2020). O sistema de diagnóstico de citologia auxiliado por inteligência artificial no rastreamento do câncer cervical em larga escala: Um estudo de coorte de base populacional de 0,7 milhão de mulheres. Cancer medicine, 9 (18), $6896-6906$.

Botero-Rosas, D. A., Murcia Garzón, C. J., Roa Barrantes, L. M., Fuentesa, J. M., \& Leon-Ariza, J. S. (2017). A novel image processing method for visualizing the vascular pattern of Human Uterine Cervix. Revista Científica General José María Córdova, 15(19), 291-306.

Brasil. Ministério da Saúde. (2017). Guia prático sobre o HPV. Guia de perguntas e respostas para profissional de saúde. Secretaria de Vigilância em Saúde. Cartilha profissionais de saúde. MS_HPV. Brasília, DF. http://portalarquivos2.saude.gov.br/images/pdf/2017/dezembro/07/Perguntas-erespostas-HPV-.pdf.

Brasil. Ministério da Saúde. (2020). Instituto Nacional do Câncer José Alencar Gomes da Silva. Estimativa 2020. Incidência do Câncer no Brasil. Rio de Janeiro: INCA.

Caixeta, R. C. A. (2014). Associação entre papilomavírus humano, vaginose bacteriana e inflamação cervical e a detecção de anormalidades no exame citológico de adolescentes e mulheres jovens. (Master dissertation, Universidade Federal de Goiás).

Casarin, M. R., \& Piccoli, J. D. C. E. (2011). Educação em saúde para prevenção do câncer de colo do útero em mulheres do município de Santo Ângelo/RS. Ciência \& saúde coletiva, 16, 3925-3932.

Costa, J. H. G., Santos, E. J. D. A., Prazeres, B. A. P. D., Andrade, M. L., Melo, M. D. F. C. D., Tsutsumi, M. Y., \& Sousa, M. S. D. (2011). Prevenção do câncer de colo do útero em comunidades ribeirinhas atendidas pelo Programa Luz na Amazônia, Estado do Pará, Brasil. Revista Pan-Amazônica de Saúde, 2(4), 17-22.

Crispim, J. E. B., Barreto, E. F., de AG Nogueira, W. B., \& de Almeida, S. A. (2018). Assistência de enfermagem à mulher lésbica e bissexual na atenção básica: protocolo de atendimento. Revista de Pesquisa: Cuidado é Fundamental Online, 10(Especial), 34-39.

Dalla Libera, L. S. (2016). Avaliação da infecção pelo Papiloma Vírus Humano (HPV) em exames citopatológicos. Brazilian Journal of Clinical Analysis, $48(2), 138-43$.

Da Silva J., W. F., \& de Almeida Araújo, L. (2020). Tendência da imunização contra o HPV na população masculina no estado do tocantins entre os anos de 2017-2019. Revista de Patologia do Tocantins, 7(2), 123-126.

Da Silva L. I., Jardim, P. D. T. C., \& Robalinho, C. F. (2020). Comportamento de jovens de Campo Grande, Mato Grosso Do Sul, frente às práticas preventivas do HPV e câncer de colo uterino. Brazilian Journal of Development, 6(9), 71866-71880.

De Almeida, A. C., \& De Oliveira, K. B. (2014). Câncer de Colo Uterino: Desenvolvimento, Diagnóstico, Tratamento e Marcadores Moleculares. Saúde e Pesquisa, 7(1).

De Freitas L. H., de Lima, S. M., de Oliveira Barbosa, J., \& de Lima, L. R. (2019). Fatores De Risco Para O Câncer Do Colo Uterino: Revisão De Literatura, $5(1)$.

De Oliveira, A. D. T., de Castro, C. E. R., Trindade Filho, J. O., de Souza Amaro, K. D., Trajano, V. N., \& Costa, H. F. (2019). Análise histopatológica do adenocarcinoma invasivo de colo uterino. Revista de Ciências da Saúde Nova Esperança, 17(1), 62-70.

De Oliveira, E. M. F., Oliveira, S. X., dos Santos Caldas, M. L. L., Oliveira, M. B., Oliveira, M. X., \& de Alencar Lima, T. N. F. (2020). A não realização do exame papanicolaou e comportamentos de risco em mulheres com vida sexual ativa. Revista Eletrônica Acervo Saúde, 12 (12), e4221.

De Sá, K. C. C., \& Silva, L. R. (2019). O exame papanicolaou na prevenção do câncer no colo uterino: uma revisão integrativa. Revista Eletrônica da Faculdade de Ceres, 8(1), 8-8. 
De Souza, A. F., \& Costa, L. H. R. (2015). Conhecimento de Mulheres sobre HPV e Câncer do Colo do Útero após Consulta de Enfermagem. Revista Brasileira de cancerologia, 61(4), 343-350.

Dias, C. F., Micheletti, V. C. D., Fronza, E., da Silva Alves, J., Attademo, C. V., \& Strapasson, M. R. (2019). Profile of cytopathologic exams collected in a family health strategy/Perfil de exames citopatológicos coletados em estratégia de saúde da família. Revista de Pesquisa: Cuidado é Fundamental Online, 11(1), 192-198.

Dos Anjos S. J. S. B., Ribeiro S. G., Lessa P. R. A., Nicolau A. I. O., Vasconcelos C. T. M., Pinheiro A. K. B. (2013). Fatores de risco para o câncer de colo do útero em mulheres reclusas. Rev Bras Enferm; 66(4): 508-13.

Dos Santos, O. R. F. (2019). A importância do enfermeiro na concientização e prevençao do hpv. Psicologia e Saúde em debate, 5(1), 80-109. Duarte, A. J. M. (2019). Estudo de diferentes abordagens terapêuticas no cancro do colo do útero (Doctoral dissertation, Universidade de Coimbra)

Eufrásio, P., Pereira, B. J., Graça, B., Palmas, A., Santiago, F., Borges, R., \& Vendeira, P. (2020). Recomendações em HPV Masculino da Sociedade Portuguesa de Andrologia, Medicina Sexual e Reprodução: Prevenção. Revista Internacional de Andrología. Doi: 10.1016/j.androl.2020.01.005

Feller, L., Wood, N. H., Khammissa, R. A., et al. (2010). HPV modulation of host immune responses. SADJ: Journal of the South African Dental Association;65(6),266-268.

Fernandes, J. V., Nascimento, G. J. F. D., \& Araújo, J. M. G. D. (2012). Correlação entre a infecção genital pelo vírus do papiloma humano, a resposta imune e os achados colpocitológicos em mulheres grávidas e não grávidas (Master's thesis, Universidade Federal do Rio Grande do Norte).

Gavidia Rojas, R. E. (2020). Conocimientos y prácticas sobre prevención del cáncer del cuello uterino en usuarias de consulta externa del Hospital Carlos Lanfranco la Hoz, Lima. (Dissertação de Mestrado da Universidad José Carlos Mariátegui).

Leite, M. F., et al. (2014). Conhecimentos e prática das mulheres sobre câncer de colo do útero de uma unidade básica de sáude. Journal of Human Growth and Development; 24(2):208-213.

Leto, M. D. G. P., Santos Júnior, G. F. D., Porro, A. M., \& Tomimori, J. (2011). Infecção pelo papilomavírus humano: etiopatogenia, biologia molecular e manifestações clínicas. Anais Brasileiros de Dermatologia, 86(2), 306-317.

Lima, E. G. D. (2011). Imunização genética para o controle de papilomaviroses: construção de um vetor vacinal baseado no Gene L2 do papilomavírus bovino tipo 1 (Master's thesis, Universidade Federal de Pernambuco).

Lodi, C. T. D. C., Lima, M. I. D. M., Meira, H. R. D. C., Souza, O. L. D., Lucena, A. A. D. S., Guimarães, M. V. M. B., \& Melo, V. H. (2012). Células escamosas atípicas cervicais: conduta clínica. Femina. 40(1), 37-42.

Marcelino, A. B., Duarte-Tavares, R. J., Marcelino, K. B., \& Silva-Neto, J. A. (2020) Câncer de colo uterino associado a fatores de risco ocupacional. Rev Bras Med Trab. 18(1):103-8.

Martínez, J. C., Pardo, I. F. M., \& Medina, R. G. (2015). Métodos actuales de diagnóstico del cáncer de cuello uterino. Medimay, 21(1), 136-146.

Neiva, G. S. M. (2013). Papilomatose de vias aéreas superiores: associação da resposta imunológica tecidual com aspectos clínicos, epidemiológicos, morfológicos e moleculares da infecção por HPV (Doctoral dissertation, Centro de Pesquisas Gonçalo Moniz).

Oliveira, S. S. S. (2016). O HPV e suas principais formas de diagnóstico. 35f. Monografia (Especialização). Instituto Nacional de Ensino Superior e Pesquisa. https://www.ccecursos.com.br/img/resumos/o-hpv-e-suas-principais-formas-de-diagn-stico-tcc---stephanny-sallome-sousa-oliveira.pdf

Peixoto, C. L. G. (2016). Papel do HPV e cofatores no cancro do colo do útero (Master's thesis, Universidade de Coimbra - Faculdade de Medicina).

Pereira, A. S., Shitsuka, D. M., Parreira, F. J., \& Shitsuka, R. (2018). Metodologia da pesquisa científica. https://repositorio.ufsm.br/bitstream/handle/1/15824/Lic_Computacao_Metodologia-Pesquisa-Cientifica.pdf?sequence=1.

Reis, M. V., \& da Piedade R. M. C. (2019). Conhecimento dos discentes sobre a vacina contra o HPV. Revista de Iniciação Científica da Universidade Vale do Rio Verde, 8(2).

Reis-Góes, F. da S., Lima, F. L. O., Amorim, C. F., \& Santa Izabel, T. dos S. (2020). Prevalence of chlamydia trachomatis infection in the brazilian female population: a review article. Research, Society and Development, 9(7), e567974483.

Rodrigues, A. L., Barros, M. F., Meirelles, S. F. D. R., \& Mantovani, D. D. P. (2020). Cobertura vacinal do HPV: uma análise sobre fatores que implicam na baixa adesão à vacina. Revista Transformar, 14(1), 560-574.

Santos, G. R. B. D. (2018). Estudo do papilomavírus humano (HPV) 18 e variantes associadas ao câncer do colo do útero em usuárias da rede SUS, São LuísMa. (Master dissertation, Universidade Federal do Maranhão).

Santos, M. S., Macêdo, A. P. N., \& Leite, M. A. G. (2010). Percepção de usuárias de uma unidade de saúde da família acerca da prevenção do câncer do colo do útero. Revista de APS, 13(3).

Serravalle, K., Levi, J. E., Oliveira, C., Queiroz, C., Dantas, Á., \& Studart, E. (2015). Comparação entre duas técnicas de genotipagem do HPV em mulheres com lesão intra-epitelial de alto grau. Revista Brasileira de Ginecologia e Obstetrícia, 37(2), 94-99.

Silva, E. R. D., Macêdo, F. L. D. S., Soares, L. R. C., Rosal, V. M. D. S., Carvalho, N. A. L., \& Rocha, M. G. D. L. (2015). Diagnóstico molecular do papilomavírus humano por captura híbrida e reação em cadeia da polimerase. Femina, 181-184.

Silva, G. P. F., Cristovam, P. C., \& Vidotti, D. B. (2017). O impacto da fase pré-analítica na qualidade dos esfregaços cervicovaginais. Revista Brasileira de Análises Clínicas, 49(2), 135-140. 
Research, Society and Development, v. 10, n. 1, e19810111634, 2021

(CC BY 4.0) | ISSN 2525-3409 | DOI: http://dx.doi.org/10.33448/rsd-v10i1.11634

Simoes, L. P., \& Junior, G. Z. (2019). Vírus HPV e o desenvolvimento de câncer de colo de útero-uma revisão bibliográfica. Revista uningá, 56(1), 98-107.

Tallon, B., Monteiro, D., Soares, L., Rodrigues, N., \& Morgado, F. (2020). Tendências da mortalidade por câncer de colo no Brasil em 5 anos (2012-2016). Saúde em Debate, 44, 362-371.

Tessarin, M. C. F., \& da Silva, M. A. M. (2017). Nutrigenômica e câncer: uma revisão. Cadernos UniFOA, 8(1), 79-96.

Wohlmeister, D. (2015). Avaliação da relação entre a infecção pelo Papilomavírus Humano e outros agentes sexualmente transmissíveis e a expressão de S100A4 em amostras cervicais. (Dissertação de mestrado da Universidade Federal do Rio Grande do Sul).

Ybaseta-Medina, J., Paccori-Rodrigo, F., \& Vilca-Yange, A. (2014). Factores clínico epidemiológicos del cáncer de cuello uterino en el Hospital Santa María del Socorro. Ica, Perú. Revista Médica Panacea, 4(3).

Yin, F, et al. (2017). A novel trivalent HPV 16/18/58 vaccine with anti-HPV 16 and 18 neutralizing antibody responses comparable to those induced by the Gardasil quadrivalent vaccine in rhesus macaque model. Papillomavirus Research; 3: 85-90.

Zandonade, E., Castro, D., Santos Neto, E. T., \& Amorim, M. (2018). Mortalidade por câncer de colo do útero no espírito santo: tendências temporais e papel da enfermagem (Master's thesis, Universidade Federal do Espírito Santo). http://repositorio.ufes.br/handle/10/8329 